Lingua Rima: Jurnal Pendidikan Bahasa dan Sastra Indonesia

Vol. 11 No. 1 Januari 2022

http://jurnal.umt.ac.id/index.php//grm

\title{
ANALISIS PEMEROLEHAN BAHASA ANAK USIA 3 TAHUN 1 BULAN (KAJIAN PSIKOLINGUISTIK)
}

\author{
Silvi Sri Rahayu ${ }^{1}$ \\ Universitas Singaperbangsa Karawang \\ Silvisrirahayusilvi23@gmail.com \\ Hendra Setiawan ${ }^{2}$ \\ Universitas Singaperbangsa Karawang
}

\begin{abstract}
ABSTRAK
Penelitian ini akan menganalisis pemerolehan bahasa pada anak usia 3 tahun 1 bulan yang meliputi tataran fonologi dan sintaksis. Pemerolehan bahasa pada manusia diawali dari anak-anak ketika belajar berbicara. Tujuan penelitian ini adalah 1) Mendeskripsikan pemerolehan bahasa anak pada tataran sitaksis melalui kajian Mean Length Of Utterence (MLU) 2) memaparkan pemerolehan bahasa anak usia 3 tahun 1 bulan dari aspek fonologi yang meliputi pemerolehan vokal, pemerolehan konsonan, dan faktor yang mempengaruhi fonologi tersebut. Metode yang digunakan pada penelitian ini adalah metode kualitatif deskriptif dengan pendekatan studi kasus. Sumber data dalam penelitian ini adalah seorang anak yang berinisial AFA. Data artikel dikumpulkan melalui observasi dan wawancara. Hasil penelitian bahwa pada usia 3 tahun 1 bulan ini tampaknya ada huruf konsonan yang dikuasi dan ada juga huruf konsosan yang belum dikuasai AFA. Terdapat dua faktor yang mempengaruhi pemerolehan bahasa fonologi anak usia 3 tahun 1 bulan yaitu faktor alat ucapnya dan faktor lingkungan atau keluarganya Tidak dibiasakannya anak dalam melafalkan ujarannya dan orang tua mengikuti melafalkan huruf vokal/ konsonan yang salah ketika berbicara dengan anak. Masyarakat yang tidak membenarkan ujaran anak tersebut membuat AFA terbiasa mengujarkan kata dengan huruf vokal atau konsonan yang salah, sehingga merasa bahwa yang diujarkannya adalah benar.
\end{abstract}

Kata Kunci: Psikolinguistik, Pemerolehan Bahasa Anak

\section{A. PENDAHULUAN}

Bahasa merupakan kemampuan yang dimiliki manusia sebagai sarana komunikasi utama dalam kehidupan di dunia baik berbentuk tulisan, lisan ataupun yang hanya berupa simbol tertentu. Chaer (2003: 167) berpendapat bahwa pemerolehan bahasa atau akuisisi merupakan proses yang berlangsung di dalam otak seorang kanak-kanak ketika dia memperoleh bahasa pertamanya atau bahasa ibunya. Ketika bahasa ibu telah diperoleh anak, maka anak akan menuju fase selanjutnya di mana ia memperoleh bahasa laon atau bahasa kedua sebagai pengetahuan baru. Ada dua proses yang terlibat dalam pemerolehan bahasa dikalangan anak, yaitu pemerolehan bahasa dan pembelajaran bahasa. Pemerolehan bahasa 


\section{Lingua Rima: Jurnal Pendidikan Bahasa dan Sastra Indonesia \\ Vol. 11 No. 1 Januari 2022 \\ http://jurnal.umt.ac.id/index.php/lgrm}

termasuk ke dalam ranah psikolinguistik. Menurut Chaer (2003: 5) Psikolinguistik mencoba menerangkan hakikat struktur bahasa dan bagaimana struktur itu diperoleh, digunakan pada waktu bertutur, dan pada waktu memahami kalimat-kalimat dalam peraturan itu. Pemerolehan bahasa pertama anak terjadi sejak semula tanpa bahasa kemudian memperoleh bahasa. Pemerolehan bahasa kedua terjadi apabila kanak-kanak atau orang dewasa telah menguasai bahasa pertama, kemudian belajar bahasa kedua secara formal dan terencana. Perkembangan bahasa kanak-kanak yang satu dengan yang lain berbeda walaupun usianya sama. Hal yang menarik dalam perkembangan pemerolehan bahasa pada kanak-kanak adalah kecepatan pemerolehannya tidak sama, tetapi tahap 2-3 tahun yang mencakupi pemerolehan vokal dan konsonan. Pada usia tersebut berada dalam priode kritis yang sangat penting dalam pemerolehan bahasa, juga karena pada usia tersebut Albar Fauzi Annadil sangat aktif berbicara.

Kajian tentang pemerolehan bahasa mencakup pemerolehan fonologi, morfologi, sintaksis dan semantik. Penguasaan atau perkembangan bahasa anak diperoleh secara bertahap. Pemerolehan fonologi merupakan ranah penelitian yang penting karena dapat menentukan atau mempengaruhi teori linguistik. Ranah penelitian fonologi sangat menarik untuk dikaji karena dalam pemerolehan bahasa kanak-kanak adalah pemunculan bunyi ini bersifat genetik. Dengan demikian pemerolehan bahasa anak sangat bervariasi. Selain itu, penelitian mengenai pemerolehan bahasa kanak-kanak dapat dikaji dengan kajian Mean Length Of Utterence ( $M L U)$. Pada periode awal anak menggunakan kalimat satu kata, kalimat dua kata, kalimat tiga kata dan seterusnya. MLU merupakan suatu konsep yang digunakan untuk mengukur prosuk linguistik yang dihasilkan seorang anak. Perhitungan MLU dilakukan dengan cara membagi bilangan morfem dengan bilangan ujaran. Semakin tinggi MLU anak, maka semakin tinggi penguasaan berbahasa anak tersebut.

Psikolinguistik merupakan suatu ilmu yang meneliti bagaimana penutur atau pemakai bahasa membangun kalimat-kalimat bahasa. Slobin (dalam Chaer, 2003: 5) mengemukakan bahwa psikolinguistik mencoba menguraikan proses-proses psikologi yang berlangsung jika seseorang mengucapkan kalimat-kalimat yang didengarnya pada waktu berkomunikasi dan bagaimana kemampuan bahasa diperoleh manusia. Secara lebih rinci Chaer (2003: 6) berpendapat bahwa psikolinguistik mencoba menerangkan hakikat struktur bahasa, dan bagaimana struktur itu diperoleh, digunakan pada waktu bertutur, dan pada waktu memahami 
Lingua Rima: Jurnal Pendidikan Bahasa dan Sastra Indonesia

Vol. 11 No. 1 Januari 2022

http://jurnal.umt.ac.id/index.php//grm

kalimat-kalimat dalam pertuturan itu. Pada hakikatnya dalam kegiatan berkomunikasi terjadi proses memproduksi dan memahami ujaran.

Menurut Galinkoff (dalamYanti, 2016: 133) mengatakan bahwa ada dua pengertian yang perlu dipahami tentang pemerolehan bahasa. Pengertian pertama mengatakan bahwa pemerolehan bahasa mempunyai suatu permulaan yang tiba-tiba dan mendadak, sedangkan pengertian kedua mengatakan bahwa pemerolehan bahasa memiliki suatu permulaan yang gradual yang muncul dari prestasi-prestasi motorik, sosial, dan kognitif pralinguistik.

Menurut Nababan (dalam Djuwarijah, 2017) Setiap anak yang normal akan belajar bahasa pertama (bahasa ibu) dalam tahun-tahun pertamanya dan proses itu terjadi hingga kirakira umur lima tahun. Chomsky (dalam Djuwarijah, 2017) berpandangan bahwa pemerolehan bahasa tidak hanya pada nurture, tetapio nature. Menurut Darwowidjojo (2010: 236) mengungkapkan bahwa setiap anak terbukti memiliki kesamaan dalam pemerolehan bahasa dan melewati proses yang sama dalam menguasai bahasa masing-masing. Lyons (dalam widyorini, 2018) mengungkapkan definisi umum tentang fonem yang dikemukakan bahwa ada dua bunyi yang secara fonetis berbeda dalam lingkungan yang sama yang sangat berpengaruh untuk membedakan kata-kata yang berlainan. Perkembangan sistem fonologi kanak-kanak dimulai jika kanak tersebut dapat mengucapkan kata pertama dalam bahasa yang benar yaitu untuk menyampaikan arti.

Pemerolehan bahasa pada tataran sintaksis berupa perhitungan panjang tuturan subjek penelitian melalui pengukuran Mean Lenght Of Utterence (MLU). Menurut Brown (dalam Widyorini, 2018:5) Cara menghitung MLU dapat dilakukan dengan beberapa langkah, pertama mengambil sampel sebanyak 100 ujaran. Kedua, menghitung jumlah morfemnya . Ketiga, membagi jumlah morfem dengan jumlah ujaran seperti pada rumus berikut.

\section{MLU= Jumlah Morfem}

Jumlah Tuturan

Brown (dalam Widyorini, 2018: 5) membagi tahap pemerolehan bahasa anak berdasarkan MLU anak menjadi sepuluh tahap, yaitu:

1. Tahap I MLU (1-1,5) pada usia 12-22 bulan

2. Tahap II MLU $(1,5-2,0)$ pada usia $22-28$ bulan

3. Tahap III MLU $(2,0-2,25)$ pada usia $27-28$ bulan 
4. Tahap IV MLU (2,25-2,5) pada usia 28-30 bulan

5. Tahap V MLU (2,5-2,75) pada usia 31-32 bulan

6. Tahap VI MLU (2,75-30,0) pada usia 33-34 bulan

7. Tahap VII MLU $(3,0-3,5)$ pada bulan 35-39 bulan

8. Tahap VIII MLU $(3,5-3,45)$ pada usia $38-40$ bulan

9. Tahap IX MLU (3,5-3,45) pada usia 41-46 bulan

10. Tahap X MLU (45+) pada usia +47 bulan.

\section{B. METODE PENELITIAN}

Metode yang digunakan dalam penelitian ini adalah metode kualitatif deskriptif dengan pendekatan studi kasus. Melalui metode ini akan dideskripsikan pemerolehan bahasa dan perkembangan fonologi AFA pada usia 3 tahun. Sumber data utama penelitian ini adalah AFA pada usia 3 tahun 1 bulan. Bahasa yang digunakan adalah bahasa Indonesia sebagai bahasa pertama/ibunya. Data dikumpulkan selama 3 minggu melalui observasi dan wawancara terhadap AFA. Teknik pengambilan data ialah simak libat cakap yang kemudian direkam melalui gawai untuk kemudian dianalis lebih jauh. Teknik analisis data menggunakan deskriptif dalam temuan penelitian

\section{HASIL PENELITIAN DAN PEMBAHASAN}

Setiap anak memiliki kemampuan yang berbeda-beda dalam pemerolehan bahasa. Dapat dikatakan seorang anak dalam memperoleh bahasa sangat bervariasi. Biasanya perebedaan dalam pemerolehan bahasa tergantung perkembanagan psikologis anak. Pada penelitian pemerolehan bahasa anak usia 3 tahun 1 bulan ini terjadi perubahan bunyi yang dialami seorang anak yang bernama AFA.

\section{Perhitungan MLU Anak Usia 3 tahun 1 bulan (Tataran Sintaksis)}

\section{Tabel 1. Pemerolehan Kalimat Satu Kata Albar}

\begin{tabular}{|c|c|c|c|c|}
\hline \multicolumn{5}{|c|}{ Kalimat Satu Kata } \\
\hline No & Ujaran & Terjemahan & $\sum \mathbf{U}$ & $\sum \mathbf{M}$ \\
\hline 1 & Galak & Galak & 1 & 1 \\
\hline 2 & Engga & Tidak & 1 & 1 \\
\hline 3 & Becal & Besar & 1 & 1 \\
\hline 4 & Rucak & Rusak & 1 & 1 \\
\hline
\end{tabular}


Lingua Rima: Jurnal Pendidikan Bahasa dan Sastra Indonesia

Vol. 11 No. 1 Januari 2022

http://jurnal.umt.ac.id/index.php//grm

\begin{tabular}{|c|l|l|l|l|}
\hline 5 & Boleh & Boleh & 1 & 1 \\
\hline 6 & Jangan! & Jangan & 1 & 1 \\
\hline
\end{tabular}

Tabel 2. Pemerolehan Kalimat Dua Kata Albar

\begin{tabular}{|c|c|c|c|c|}
\hline \multicolumn{5}{|c|}{ Kalimat Dua Kata } \\
\hline No & Ujaran & Terjemahan & $\sum \mathbf{U}$ & $\sum \mathbf{M}$ \\
\hline 1 & Olennya/ becal & Orennya/ besar & 2 & 2 \\
\hline 2 & Itu ondel-ondel & Itu ondel-ondel & 1 & 2 \\
\hline 3 & Ondel-ondel pocong & Ondel-ondel pocong & 1 & 2 \\
\hline 4 & Ondelnya melah & Ondelya merah & 1 & 2 \\
\hline 5 & Uwa ciapa? & Uwa siapa? & 1 & 2 \\
\hline 6 & Muka ciapa? & Muka siapa? & 1 & 2 \\
\hline 7 & Bajunya belu & Bajunya blue (biru) & 1 & 2 \\
\hline 8 & Baju/ belu & Baju/ blue (biru) & 2 & 2 \\
\hline 9 & Cama Mbu & Sama Ibu & 1 & 2 \\
\hline 10 & Cama Ayah & Sama Ayah & 1 & 2 \\
\hline 11 & Cama Ateu & Sama Ateu & 1 & 2 \\
\hline 12 & Udah/tadi & Sudah/ tadi & 2 & 2 \\
\hline 13 & Ke Amih & Ke Amih & 1 & 2 \\
\hline 14 & Ambil ateu! & Ambil ateu! & 1 & 2 \\
\hline 15 & Baju balu & Baju baru & 1 & 2 \\
\hline
\end{tabular}

Tabel 3. Pemerolehan Kalimat Tiga Kata Albar

\begin{tabular}{|c|l|l|l|l|}
\hline \multicolumn{2}{|c|}{ Kalimat Tiga Kata } \\
\hline No & \multicolumn{1}{|c|}{ Ujaran } & \multicolumn{1}{c|}{ Terjemahan } & \multicolumn{2}{c|}{$\sum \mathbf{U}$} \\
\hline 1 & Ondel/ giginya takut. & Ondel/ giginya takut. & 2 & 3 \\
\hline 2 & Takut si epe & Takut si epe & 1 & 3 \\
\hline 3 & itu ondel-ondel apa? & itu ondel-ondel apa? & 1 & 3 \\
\hline
\end{tabular}


Lingua Rima: Jurnal Pendidikan Bahasa dan Sastra Indonesia

Vol. 11 No. 1 Januari 2022

http://jurnal.umt.ac.id/index.php//grm

\begin{tabular}{|c|l|l|l|l|}
\hline 4 & Inimah cepeda cepidslman. & Ini sepeda Spiderman. & 1 & 3 \\
\hline 5 & Muka/ yang ini? & Muka/ yang ini? & 1 & 3 \\
\hline 6 & Ngga jadi apa? & Ngga jadi apa? & 1 & 1 \\
\hline 7 & Naik kuda yuk! & Naik kuda yuk! & 1 & 3 \\
\hline 8 & Ikut cama ateu & Ikut sama ateu & 1 & 3 \\
\hline 9 & Itu ada Celatus? & Itu ada seratus? & 1 & 3 \\
\hline 10 & Cəlatus belapa ateu? & Seratus berapa ateu? & 1 & 3 \\
\hline 11 & Oh banyak teu. & Oh banyak teu. & 1 & 3 \\
\hline 12 & Itu motolnya ateu! & Itu motornya ateu! & 1 & 3 \\
\hline 13 & Hayu ateu kabul! & Hayu ateu kabur! & 3 \\
\hline
\end{tabular}

Tabel 4. Pemerolehan Kalimat Empat Kata Albar

\begin{tabular}{|c|c|c|c|c|}
\hline \multicolumn{5}{|c|}{ Kalimat Empat Kata } \\
\hline No & Ujaran & Terjemahan & $\sum \mathbf{U}$ & $\sum \mathbf{M}$ \\
\hline 1 & cama/ ondel-ondel cama kuda & sama/ ondel-ondel sama kuda & 2 & 4 \\
\hline 2 & Yang kecilmah ngga jalan & Yang kecilnya tidak jalan & 1 & 4 \\
\hline 3 & Yang gede jalan rucak & Yang besar jalan rusak & 1 & 4 \\
\hline 4 & Yang inimah/ ngga takut. & Yang ini/ tidak takut. & 2 & 4 \\
\hline 5 & Tadi/ kuda udah lewat & Tadi/ kuda udah lewat & 2 & 4 \\
\hline 6 & Zea mah punya pespa & Zea mah punya vespa & 1 & 4 \\
\hline 7 & Yang putih mah takut & Kalau yang putih takut & 1 & 4 \\
\hline 8 & Takut ateu/ badut besal & Takut ateu/ badut besar & 2 & 4 \\
\hline 9 & Sama ateu ke Aglonyaa & Sama ateu ke Agronyaa & 1 & 4 \\
\hline 10 & Hayu atuh ateu ih! & Hayu atuh ateu ih! & 1 & 4 \\
\hline 11 & Baik ateu/ Galak badutnya & Baik ateu/ Galak badutnya & 2 & 4 \\
\hline 12 & Nanti badutnya ikut teu? & Nanti badutnya ikut teu? & 1 & 4 \\
\hline 13 & Udah diambil kuda /cahayanya? & Udah diambil kuda /cahayanya? & 2 & 4 \\
\hline 14 & Udah minta buah udah & Udah minta buah udah & 1 & 4 \\
\hline 15 & onden mau pulang ateu & onden mau pulang ateu & 1 & 4 \\
\hline 16 & Celem ateu/ becal badutnya & Seram ateu/ besar badutnya & 2 & 4 \\
\hline
\end{tabular}


Lingua Rima: Jurnal Pendidikan Bahasa dan Sastra Indonesia

Vol. 11 No. 1 Januari 2022

http://jurnal.umt.ac.id/index.php//grm

Tabel 5. Pemerolehan Kalimat Lima Kata Albar

\begin{tabular}{|c|c|c|c|c|}
\hline \multicolumn{5}{|c|}{ Kalimat Lima Kata } \\
\hline No & Ujaran & Terjemahan & $\sum \mathbf{U}$ & $\sum \mathbf{M}$ \\
\hline 1 & Uwa ipan/ Dibeliin cama mamahnya. & Uwa ivan/ Dibeliin sama mamahnya. & 2 & 5 \\
\hline 2 & Jea mah gak punya cepedah & Zea mah gak punya sepedah & 1 & 5 \\
\hline 3 & Yang merah mah enggak takut & Yang merah mah enggak takut & 1 & 5 \\
\hline 4 & ənden mau beli baju melah & ənden mau beli baju merah & 1 & 5 \\
\hline 5 & Nunggu kuda di cini ah & Nunggu kuda di sini ah & 1 & 5 \\
\hline 6 & Badut melah cama badut ijo & Badut merah sama badut hijau & 1 & 5 \\
\hline 7 & takut badut/ ateu takut badut & takut badut/ ateu takut badut & 2 & 5 \\
\hline 8 & Banyak belapa ateu Selatus belapa? & Banyak berapa ateu Seratus berapa? & 1 & 5 \\
\hline 9 & Selatus libu apa selatus/ banyak? & Selatus ribu apa seratus/ banyak? & 2 & 5 \\
\hline
\end{tabular}

Tabel 6. Pemerolehan Kalimat Enam Kata Albar

\begin{tabular}{|c|l|l|l|l|}
\hline \multicolumn{5}{|c|}{ Kalimat Enam Kata } \\
\hline No & \multicolumn{1}{|c|}{ Ujaran } & \multicolumn{1}{|c|}{ Terjemahan } & $\sum$ U \\
\hline 1 & Sama yang melah sama yang beulu & Sama yang merah sama yang blue & 1 & 6 \\
\hline 2 & onden mah/ udah belangkat ke cana & Nden mah/ udah berangkat ke sana & 2 & 6 \\
\hline 3 & Nanti/ ateu mah ngga kemana-mana? & Nanti/ ateu mah ngga kemana-mana? & 2 & 6 \\
\hline 4 & Engga mau ateu/ hayu pulang, ateu! & Engga mau ateu/ hayu pulang, ateu! & 2 & 6 \\
\hline 5 & Kata embu galak ateu/ galak badutnya. & Kata embu galak ateu/ galak badutnya. & 2 & 6 \\
\hline 6 & Baik bukan ateu/ badutnya baik ya? & Baik bukan ateu/ badutnya baik ya? & 2 & 6 \\
\hline
\end{tabular}

Tabel 7. Pemerolehan Kalimat Tujuh Kata Albar

\begin{tabular}{|c|c|c|c|c|}
\hline \multicolumn{5}{|c|}{ Kalimat Tujuh Kata } \\
\hline No & Ujaran & Terjemahan & $\sum \mathbf{U}$ & $\sum \mathbf{M}$ \\
\hline 1 & $\begin{array}{l}\text { Ateu mah hayu hayu telus/ pelginya } \\
\text { lama. }\end{array}$ & $\begin{array}{l}\text { Ateu mah hayu hayu terus/ perginya } \\
\text { lama. }\end{array}$ & 2 & 7 \\
\hline 2 & $\begin{array}{l}\text { Dimana motolnya ateu/ Banyak } \\
\text { motolnya/ ada cepuluh }\end{array}$ & $\begin{array}{l}\text { Dimana motornya ateu/ Banyak } \\
\text { motornya/ ada cepuluh }\end{array}$ & 3 & 7 \\
\hline 3 & Baju melah ini/ yang/ kaya ondel-ondel & Baju meRah ini/ yang/ kaya ondel- & 2 & 7 \\
\hline
\end{tabular}


Lingua Rima: Jurnal Pendidikan Bahasa dan Sastra Indonesia

Vol. 11 No. 1 Januari 2022

http://jurnal.umt.ac.id/index.php//grm

\begin{tabular}{|l|l|l|l|l|}
\hline & ateu & ondel ateu & & \\
\hline
\end{tabular}

Tabel 8. Pemerolehan Kalimat Delapan Kata Albar

\begin{tabular}{|c|l|l|c|c|}
\hline \multicolumn{5}{|c|}{ Kalimat Delapan Kata } \\
\hline No & \multicolumn{1}{|c|}{ Ujaran } & \multicolumn{1}{|c|}{ Terjemahan } & $\sum \mathbf{U}$ \\
\hline 1 & $\begin{array}{l}\text { Kata widi badutnya galak ateu/ Dua } \\
\text { badutnya galak. }\end{array}$ & $\begin{array}{l}\text { Kata widi badutnya galak ateu/ Dua } \\
\text { badutnya galak. }\end{array}$ & 2 & 8 \\
\hline 2 & $\begin{array}{l}\text { Ini upin ipin yang kuning/ cama yang } \\
\text { beulu }\end{array}$ & $\begin{array}{l}\text { Ini upin ipin yang kuning/ cama yang } \\
\text { blue }\end{array}$ & 2 & 8 \\
\hline
\end{tabular}

Tabel 9. Pemerolehan Kalimat Sembilan Kata Albar

\begin{tabular}{|c|l|l|l|l|}
\hline \multicolumn{5}{|c|}{ Kalimat Sembilan Kata } \\
\hline No & \multicolumn{1}{|c|}{ Ujaran } & \multicolumn{1}{|c|}{ Terjemahan } & \\
\hline 1 & $\begin{array}{l}\text { Tuh ondel-ondel/ ondel-ondel putih } \\
\text { sama ondel-ondel beulu bukan teu }\end{array}$ & $\begin{array}{l}\text { Tuh ondel-ondel/ ondel-ondel putih } \\
\text { sama ondel-ondel beulu bukan teu }\end{array}$ & 2 & 9 \\
\hline 2 & $\begin{array}{l}\text { Cucah bawa ondelnya cama kudanya/ } \\
\text { belat kudanya/ ambil banyak }\end{array}$ & $\begin{array}{l}\text { Cucah bawa ondelnya cama kudanya/ } \\
\text { belat kudanya/ ambil banyak }\end{array}$ & 3 & 9 \\
\hline
\end{tabular}

Tabel 10. Jumlah Pemerolehan Kata dalam Kalimat

\begin{tabular}{|c|l|c|c|}
\hline No & Kata Dalam Satu Kalimat & $\sum \mathbf{U}$ & $\sum \mathbf{M}$ \\
\hline 1 & Kakimat Satu Kata & 6 & 6 \\
\hline 2 & Kalimat Dua Kata & 18 & 30 \\
\hline 3 & Kalimat Tiga Kata & 14 & 39 \\
\hline 4 & Kalimat Empat Kata & 23 & 64 \\
\hline 5 & Kalimat Lima Kata & 12 & 45 \\
\hline 6 & Kalimat Enam Kata & 7 & 21 \\
\hline 7 & Kalimat Tujuh Kata & 4 & 16 \\
\hline 8 & Kalimat Delapan Kata & 5 & 18 \\
\hline 9 & Kalimat Sembilan Kata & & \\
\hline
\end{tabular}


Lingua Rima: Jurnal Pendidikan Bahasa dan Sastra Indonesia

Vol. 11 No. 1 Januari 2022

http://jurnal.umt.ac.id/index.php//grm

\begin{tabular}{|c|c|c|}
\hline Jumlah & 100 & 275 \\
\hline
\end{tabular}

JUMLAH MORFEM 275

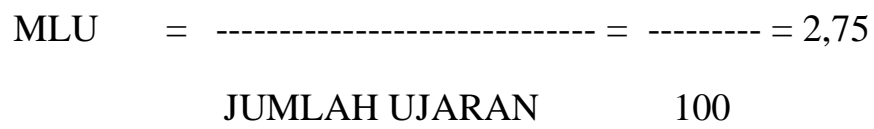

Berdasarkan perhitungan MLU di atas, Panjang ujaran Albar adalah 2,75 kata perujaran. Bila, disesuaikan dengan pendapat Brown, MLU Albar sesuai dengan tahap yang seharusnya. Tahap untuk usia 3 tahun 1 bulan adalah tahap VI usia $(2,75-3,0)$. Berdasarkan data tersebut, maka Albar dinyatakan memiliki kesempurnaan ujaran diusianya.

\section{Analisis Data Pemerolehan Tataran Fonologis}

Berdasarkan data yang diperoleh dalam penelitian dapat dikemukakan bahwa Albar memaparkan bunyi bahasa sebagai berikut.

Tabel 11. Pemerolehan Bunyi Albar

\begin{tabular}{|c|c|c|c|c|}
\hline No & Bunyi & Data & Makna Sebenarnya & Keterangan \\
\hline 1 & $/ \mathrm{a} /$ & Apa & Apa & Vokal \\
\hline 2 & $/ \mathrm{c} /$ & Capa & Siapa & Konsonan \\
\hline 3 & $/ \mathrm{c} /$ & Ke cana & Ke sana & Konsonan \\
\hline 4 & $/ 1 /$ & Olen & Oren & Konsonan \\
\hline 5 & $/ 1 /$ & Tluk & Truk & Konsonan \\
\hline 6 & $/ \mathrm{O} /$ & Ondel-Ondel & Ondel-Ondel & Reduplikasi \\
\hline 7 & $/ \mathrm{m} /$ & Mbu & Ibu & Konsonan \\
\hline 8 & $/ \partial /$ & cepidclman & Spiderman & Vokal \\
\hline 9 & /ə/ & Belu & Blue (biru) & Vokal \\
\hline 10 & $/ \mathrm{c} /$ & Celem & Seram & Konsonan \\
\hline 11 & /ə/ & onden & ənden (Albar) & Vokal \\
\hline 12 & $/ \mathrm{l} /$ & Colatus & Seratus & Vokal \\
\hline 13 & $\mid \varepsilon /$ & pelginya & Perginya & Vokal \\
\hline 14 & $/ \mathrm{c} /$ & Rucak & Rusak & Konsonan \\
\hline 15 & $/ \mathrm{p} /$ & Pespa & Vespa & Konsonan \\
\hline
\end{tabular}




\section{Lingua Rima: Jurnal Pendidikan Bahasa dan Sastra Indonesia \\ Vol. 11 No. 1 Januari 2022 \\ http://jurnal.umt.ac.id/index.php//grm}

Berdasarkan analisis tabel di atas dapat dinyatakan bahwa Albar yang berusia 3 tahun 1 bulan telah menguasai huruf-huruf vokal seperti (a,i,u,e,o,ə, $\varepsilon$ ). Pelafalan /ə/ sangat fasih dan sering digunakan. Albar telah bisa melafalkan huruf-huruf yang dikuasainya meskipun hurufhuruf tersebut terletak pada bagian awal, tengah, atau akhir. Variasi pada pelafalan huruf vokal untuk masing-masing bunyi sudah jelas diujarkannya.

Kemudian, berdasarkan analisis tabel di atas pula, Albar tidak menguasai huruf-huruf konsonan seperti ( $\mathrm{r}, \mathrm{l}, \mathrm{v}$ dan $\mathrm{s}$ ). Seringkali terjadi perubahan ujaran atau perubahan bunyi pada kata jika ada huruf tersebut. Pada usia 3 tahun 1 bulan ini tampaknya ada huruf konsonan yang dikuasi dan ada juga huruf konsosan yang belum dikuasai Albar. Meskipun sudah menguasai beberapa huruf konsosan tetapi masih terdapat kekeliruan dengan bunyi huruf yang lainnya. Saat mengujarkan kata yang terdapat huruf konsonan /r/ maka konsonan yang diujarkan berubah menjadi /1/. Jika terdapat huruf konsonan /1/ pengujaran tidak begitu jelas. Selain konsonan /r/ dan /l/, Albar memiliki kesulitan dalam melafalkan konsonan /s/ yang langsung berubah ke konsonan /c/ dan konsonan /v/ yang terdengar seperti konsonan /p/.

Hasil analisis yang sudah dilakukan memperlihatkan bahwa terdapat faktor yang mempengaruhi pemerolehan bahasa anak usia 3 tahun 1 bulan. Faktor tersebut juga mempengaruhi pemerolehan Fonologi Albar. Faktor yang menyebabkan terjadinya ketidaksempurnaan ujaran AFA adalah alat ucapnya. Meskipun sudah dilakukan cara terus memancing anak atau dengan cara mengajari dengan pelan-pelan secara dieja, anak tersebut tidak dapat melakukan ujaran kata-kata yang terdapat huruf-huruf sulit, seperti saat mengalami kesulitan pada huruf konsonan. Kemudian, faktor lain pemerolehan bahasa yang terjadi pada anak di uisa 3 tahun 1 bulan ini yaitu karena faktor lingkungan atau faktor keluarganya. Pada awal anak berujar, orang tua membiarkan anak melafalkan ujaran yang salah. Dalam bahasa sunda, orang tua yang terlalu menyayangi anaknya dan melafalkan katakata manja disebut "geugeut". Sehingga orang tua mengikuti apa yang diujarkan oleh anak tersebut walaupun menggunakan huruf vokal atau konsonan yang salah.

\section{SIMPULAN DAN SARAN}

Berdasarkan analisis tabel di atas dapat dinyatakan bahwa AFA yang berusia 3 tahun tidak mengalami keterlambatan dalam berbicara berdasarkan perhitungan Mean Length Of Utterence (MLU) oleh Brown dan menguasai huruf-huruf vokal seperti (a,i,u,e,o,ə, $\varepsilon$ ). Kemudian, berdasarkan analisis tabel di atas pula, Albar tidak menguasai huruf-huruf 
Lingua Rima: Jurnal Pendidikan Bahasa dan Sastra Indonesia

Vol. 11 No. 1 Januari 2022

http://jurnal.umt.ac.id/index.php/lgrm

konsonan seperti ( $\mathrm{r}, 1, \mathrm{v}$ dan s). Seringkali terjadi perubahan ujaran atau perubahan bunyi pada kata jika ada huruf tersebut. Pada usia 3 tahun 1 bulan ini tampaknya ada huruf konsonan yang dikuasi dan ada juga huruf konsosan yang belum dikuasai AFA. Terdapat dua faktor yang mempengaruhi pemerolehan bahasa fonologi anak usia 3 tahun 1 bulan yaitu faktor alat ucapnya dan faktor lingkungan atau keluarganya Tidak dibiasakannya anak dalam melafalkan ujarannya dan orang tua mengikuti melafalkan huruf vokal/ konsonan yang salah ketika berbicara dengan anak. Kemudian, lingkungan yang tidak membenarkan ujaran anak tersebut membuat AFA terbiasa mengujarkan kata dengan huruf vokal atau konsonan yang salah, sehingga merasa bahwa yang diujarkannya adalah benar.

\section{E. DAFTAR PUSTAKA}

Chaer, Abdul. (2003). PSIKOLINGUISTIK: KAJIAN TEORITIK. Jakarta: Rineka Cipta

Djuwarijah, Siti. (2017). PEMEROLEHAN BAHASA TELEGRAM DAN KALIMAT ANAK USIA PRASEKOLAH DAN SD. KONSTRUKTIVISME, Vol. 9, No. 1

Widyorini, Marlina Dwisisi. (2018). Pemerolehan Bahasa pada Anak usia 2-3 Tahun Melalui Metode Bernyayi di PAUD Nur Insani . Piyaman, Wonosari, Gunungkidul. Medan Makna Vol. XVI No.2.

Yanti, Prima Gusti. (2016). Pemerolehan Bahasa Anak: Kajian Aspek Fonologi Pada Anak Usia 2-2,5 Tahun. PPTK PAUDNI Vol.11 No.2. 